\title{
Selective Expression of a Sodium Pump Isozyme by Cough Receptors and Evidence for Its Essential Role in Regulating Cough
}

\author{
Stuart B. Mazzone, ${ }^{1}$ Sandra M. Reynolds, ${ }^{2}$ Nanako Mori, ${ }^{2}$ Marian Kollarik, ${ }^{2}$ David G. Farmer, ${ }^{2}$ Allen C. Myers, ${ }^{2}$ \\ and Brendan J. Canning ${ }^{2}$ \\ ${ }^{1}$ School of Biomedical Sciences, The University of Queensland, St Lucia, Queensland 4072, Australia, and 2The Johns Hopkins Asthma and Allergy Center, \\ Baltimore, Maryland 21224
}

We have identified a distinct subtype of airway vagal afferent nerve that plays an essential role in regulating the cough reflex. These afferents are exquisitely sensitive to punctate mechanical stimuli, acid, and decreases in extracellular chloride concentrations, but are insensitive to capsaicin, bradykinin, histamine, adenosine, serotonin, or changes in airway intraluminal pressures. In this study we used intravital imaging, retrograde neuronal tracing, and electrophysiological analyses to characterize the structural basis for their peculiar mechanical sensitivity and to further characterize the regulation of their excitability. In completing these experiments, we uncovered evidence for an essential role of an isozyme of $\mathrm{Na}^{+}-\mathrm{K}^{+}$ATPase in regulating cough. These vagal sensory neurons arise bilaterally from the nodose ganglia and are selectively and brilliantly stained intravitally with the styryl dye FM2-10. Cough receptor terminations are confined and adherent to the extracellular matrix separating the airway epithelium and smooth muscle layers, a site of extensive remodeling in asthma and chronic obstructive pulmonary disease. The cough receptor terminals uniquely express the $\alpha_{3}$ subunit of $\mathrm{Na}^{+}-\mathrm{K}^{+}$ATPase. Intravital staining of cough receptors by FM2-10, cough receptor excitability in vitro, and coughing in vivo are potently and selectively inhibited by the sodium pump inhibitor ouabain. These data provide the first detailed morphological description of the peripheral terminals of the sensory nerves regulating cough and identify a selective molecular target for their modulation.

\section{Introduction}

The cough reflex protects the airways and lungs from aspiration, inhaled particulates, and irritants, and facilitates clearance of accumulated secretions. A dysfunctional cough reflex can have acute, dire consequences and is a major risk factor for life threatening pneumonias in patients with neuromuscular disorders and stroke. Cough can also be problematic, especially acutely following upper respiratory tract infection and in chronic diseases including asthma, gastroesophageal reflux disease and chronic obstructive pulmonary disease (Irwin et al., 2006; Morice et al., 2006).

It is well established that coughing is preserved following general anesthesia but abolished by vagotomy, suggesting an essential role for vagal afferent nerves. However, precisely which afferent nerve subtypes regulate cough has been the subject of considerable debate and disagreement (Canning et al., 2006b). Activation of rapidly adapting airway mechanoreceptors (RARs) and bronchopulmonary C-fibers, both of which mediate other airway defensive reflexes, is most often implicated in cough. But

Received Sept. 10, 2008; revised Aug. 22, 2009; accepted Aug. 26, 2009.

This study was funded by the National Institutes of Health, Bethesda, MD (National Heart, Lung, and Blood Institute Grant HL083192). S.B.M. is a National Health and Medical Research Council of Australia R. D. Wright Fellow (\#454776).

Correspondence should be addressed to Brendan J. Canning, The Johns Hopkins Asthma and Allergy Center, 5501 Hopkins Bayview Circle, Baltimore, MD 21224. E-mail: bjc@jhu.edu.

DOI:10.1523/JNEUROSCI.4354-08.2009

Copyright $\odot 2009$ Society for Neuroscience ～0270-6474/09/2913662-10\$15.00/0
RAR and C-fiber selective stimuli are not effective at evoking cough under many experimental conditions (Canning et al., 2004). For example, C-fibers are completely ineffective at initiating cough in anesthetized animals and yet cough is not abolished by anesthesia. Similarly, RAR selective stimuli, such as inspiratory efforts against a closed glottis or the bronchoconstrictors histamine, substance $\mathrm{P}$, methacholine and the cysteinyl-leukotrienes are also ineffective at initiating cough in awake or anesthetized animals. The available evidence suggests that anesthesia selectively inhibits coughing evoked by C-fibers, while the role of RARs in cough remains unclear. The results also suggest the involvement of other airway afferent nerve subtypes in cough (Canning et al., 2004; Chou et al., 2008).

We have described an acid sensitive, capsaicin-insensitive vagal afferent mechanoreceptor innervating the large airways that plays an essential role in regulating cough (Canning et al., 2004). These "cough receptors" are differentiated from C-fibers by their action potential conduction velocity, mechanical sensitivity and insensitivity to capsaicin, bradykinin, serotonin and adenosine. Cough receptors can also be differentiated from RARs and slowly adapting stretch receptors (SARs) innervating the lungs, as they are insensitive to changes in airway luminal pressure, smooth muscle contraction or stretch. The cough receptors also conduct action potentials at much slower velocities than RARs or SARs and unlike the stretch receptors, terminate almost exclusively in the extrapulmonary airways. Given their sites of termination (larynx, trachea and mainstem bronchi) and exquisite sensitivity to 
punctate mechanical stimuli and acid, cough receptors are ideally situated and responsive to initiate cough following aspiration, inhalation of particulate matter or in response to accumulated secretions.

We have designed experiments to further characterize the afferent nerves regulating cough. We discovered a subset of sensory nerve terminals in the extrapulmonary airway mucosa of guinea pigs that were selectively and brilliantly labeled intravitally by the fluorescent styryl dye FM2-10. Subsequent experiments revealed that these nerve endings corresponded to the peripheral terminals of the cough receptors. We found that the intense and specific labeling of the cough receptor terminals by FM2-10 may be dependent upon the expression and actions of an isozyme of the sodium pump. We provide evidence for an essential role of this isozyme in the initiation of cough.

\section{Materials and Methods}

Ethics approval, tissue preparation, and labeling with FM2-10. With the approval of the institutional Animal Care and Use Committee, male Hartley guinea pigs were killed by asphyxiation in $100 \% \mathrm{CO}_{2}$ and exsanguinated. Their tracheae were removed, placed in oxygenated $(95 \%$ $\mathrm{O}_{2} / 5 \% \mathrm{CO}_{2}$ ) Krebs buffer (composition (mM): NaCl, 118; $\mathrm{KCl}, 5.4$; $\mathrm{NaHPO}_{4}, 1 ; \mathrm{MgSO}_{4}, 1.2 ; \mathrm{CaCl}_{2}, 1.9 ; \mathrm{NaHCO}_{3}, 25$; dextrose, 11.1), cut into segments (6-10 cartilage rings), attached to either tungsten rods or platinum electrodes, and placed in organ baths filled with warmed, oxygenated buffer containing $1 \mu \mathrm{M}$ atropine to limit muscarinic receptor labeling (Mazzone et al., 2006).

After 60 min equilibration in Krebs, tissues were stained with FM2-10 (Invitrogen) by adding the dye directly to the organ bath. In 4 preliminary experiments, we determined optimal incubation concentration (50 $\mu \mathrm{M})$ and duration (20 min) for FM2-10 staining. After staining, tissues were washed thoroughly and transferred to a viewing chamber containing fresh Krebs buffer. Tracheae were cut longitudinally along their ventral surface and pinned flat with their luminal surfaces facing upward. The epithelium was removed by rubbing with a cotton swab. FM2-10 labeled structures were visualized using an Olympus BX60 epifluorescent microscope. Images were captured digitally using a Pixera Penguin 600CL cooled CCD digital camera and imported into Adobe Photoshop (version 6).

In 3 animals the effects of vagotomy on FM2-10 staining was evaluated. Guinea pigs were anesthetized $(50 \mathrm{mg} / \mathrm{kg}$ ketamine and $2.5 \mathrm{mg} / \mathrm{kg}$, i.m. xylazine) and an incision was made in the neck. The left $(n=2)$ or right $(n=1)$ cervical vagus nerve was located and a $10 \mathrm{~mm}$ section of the nerve (caudal to the nodose ganglion) was removed. The incision was sutured and animals were left to recover for $\geq 7 \mathrm{~d}$ before tracheae harvest for FM2-10 staining. In other preparations, FM2-10 labeling was performed following organotypic culture for $24-48 \mathrm{~h}$, with or without extrinsic innervation intact. The organotypic culture methods have been described in detail previously (Canning et al., 1996). Tissue viability following organotypic culture was confirmed using adjacent tracheal segments and in vitro functional studies of electrically evoked cholinergic contractions (data not shown).

Mechanistic studies of FM2-10 labeling. We compared FM2-10 labeling (1) with and without concomitant electrical field stimulation (EFS; $10 \mathrm{~V}$, $2-32 \mathrm{~Hz}, 1 \mathrm{~ms}$ pulses, for the duration of the staining, (2) at $37^{\circ} \mathrm{C}$, room temperature $\left(22^{\circ} \mathrm{C}\right)$ or at $4^{\circ} \mathrm{C}$, and $(3)$ in normal and in calcium deficient buffer containing $100 \mu \mathrm{M}$ EDTA ( $n=3-7$ each). We also tried to reverse FM2-10 labeling by electrically $(10 \mathrm{~V}, 32 \mathrm{~Hz}, 1 \mathrm{~ms}$ pulses for $10 \mathrm{~min}$ ) or chemically [ $90 \mathrm{~mm}$ potassium; $10 \mu \mathrm{M}$ capsaicin (Sigma) and $3 \mu \mathrm{M}$ bradykinin (Sigma)] stimulating the tissues post-staining $(n=4$ each).

FM2-10 labeling in the absence and presence ( $n=2-4$ each) of $1 \mu \mathrm{M}$ tetrodotoxin (TTX, fast sodium channels), $1 \mathrm{~mm} 4$-aminopyridine (4$\mathrm{AP}$, potassium channels), $100 \mu \mathrm{M}$ amiloride [epithelial sodium channels (ENaC) ], $100 \mu \mathrm{M}$ PPADS (P2X 2 receptors), $100 \mu \mathrm{M}$ capsazepine (TRPV1 receptors), or $3 \mu \mathrm{M}$ gadolinium (blocks several mechanotransduction channels) and 0.1-10 $\mu \mathrm{m}$ ouabain (to block $\mathrm{Na}^{+}-\mathrm{K}^{+}$ATPase) (Sigma) was also evaluated. Tissues were preincubated with each drug for $20 \mathrm{~min}$ in the absence of the dye and for a further $20 \mathrm{~min}$ in the presence of the dye before washing and visualization.
Retrograde neuronal tracing. Anesthetized ( $50 \mathrm{mg} / \mathrm{kg}$ ketamine and 2.5 $\mathrm{mg} / \mathrm{kg}$, i.m. xylazine) guinea pigs $(n=9)$ or rats $(n=3)$ received $5 \mu \mathrm{l}$ of $3 \%$ fast blue (Sigma) into the lumen of the extrathoracic trachea via a small incision in the neck (Mazzone and Canning, 2002). In other experiments, unilateral (left or right) sectioning of a superior (SLN) or recurrent (RLN) laryngeal nerve was performed before tracer injection $(n=3$ each). Animals survived up to $12 \mathrm{~d}$ and were then deeply anesthetized with sodium pentobarbital and transcardially perfused with $10 \mathrm{~mm}$ heparinized PBS containing $0.1 \%$ procaine followed by $4 \%$ paraformaldehyde. The nodose and jugular ganglia were removed, frozen in OCT and sectioned $(12 \mu \mathrm{m})$. The number of fast blue-labeled neurons was counted in sections of the ganglia, which were also used for immunohistochemical staining (see below).

Wholemount and slice immunohistochemistry. Guinea pigs $(n=9)$ and rats $(n=3)$ were deeply anesthetized with $100 \mathrm{mg} / \mathrm{kg}$ sodium pentobarbital and transcardially perfused with $10 \mathrm{~mm}$ heparinized PBS containing $0.1 \%$ procaine. Tracheae were fixed in $4 \%$ paraformaldehyde for $2 \mathrm{~h}$ and then dehydrated through ascending concentrations of ethanol (30 min per step), cleared in xylene (20 min), rehydrated back through descending concentrations of ethanol, and washed in PBS. Wholemounts were covered in blocking solution (10\% goat serum, 1\% BSA, 0.5\% Tween 20 in PBS) for $1 \mathrm{~h}$ and then incubated overnight at $37^{\circ} \mathrm{C}$ with (1) a polyclonal rabbit antibody to the pan-neuronal marker, protein gene product (PGP) 9.5 (1:400, Millipore Bioscience Research Reagents); (2) a monoclonal rat antibody to substance P (1:200, Millipore Bioscience Research Reagents); or (3) a monoclonal mouse antibody to the $\alpha_{3}$ subunit of $\mathrm{Na}^{+}-\mathrm{K}^{+}$ATPase (clone XVIF9G10, 1:600, Biomol International, Plymouth Meeting, PA). Staining was detected with rhodamine- or fluorescein-conjugated goat antirabbit/rat/mouse IgG (1:200 dilution, Invitrogen).

For immunohistochemical staining of fast blue labeled nodose and jugular ganglia neurons (Mazzone and Canning, 2002), sections were incubated overnight (at $4^{\circ} \mathrm{C}$ ) with monoclonal rat anti-substance $\mathrm{P}$ (1:400, Millipore Bioscience Research Reagents), washed, and incubated ( $1 \mathrm{~h}$, room temperature) with fluorescein-conjugated goat anti-rat IgG (1:200 dilution). Labeling in a minimum of 5 sections/ganglia was analyzed.

Functional studies in anesthetized guinea pigs and rats. Functional experiments were performed on anesthetized ( $1.5 \mathrm{~g} / \mathrm{kg}$, i.p. urethane) guinea pigs and rats as previously described (Canning et al., 2004). Animals were breathing freely via a cannula sutured into the caudal extrathoracic trachea. Pressure was measured via a side port and respiratory efforts were recorded digitally using a Biopac data acquisition system (Biopac). The bypassed segment of the extrathoracic trachea was opened lengthwise and perfused with Krebs bicarbonate buffer containing $3 \mu \mathrm{M}$ indomethacin. Respiratory reflexes were evoked by mechanically probing the tracheal or laryngeal mucosa with a $1 \mathrm{mN}$ von Frey filament (Canning et al., 2004). Responses were also evoked electrically (1-32 Hz, $1-12 \mathrm{~V}, 1 \mathrm{~ms}$ pulse duration, $10 \mathrm{~s}$ train) using a custom-made bipolar platinum electrode placed onto the tracheal or laryngeal mucosa, and chemically by administering capsaicin $(10 \mu \mathrm{M})$ directly to the tracheal perfusate, or with citric acid administered as a $100 \mu \mathrm{l}$ bolus $(0.001-2 \mathrm{M})$.

Electrophysiological recordings of trachea afferent fibers in vitro. Guinea-pig tracheae with intact right-side vagal innervation were isolated and placed in a custom built recording chamber. A ventral longitudinal cut exposed the luminal surface of the trachea. The nodose and jugular ganglia, along with the rostral-most vagus and superior laryngeal nerves, were pulled through a small hole into an adjacent compartment of the same chamber for recording single fiber activity. Both compartments were perfused with Krebs buffer (6-8 $\mathrm{ml} \mathrm{min}^{-1}, 35^{\circ} \mathrm{C}, \mathrm{pH} 7.4$ ) containing $3 \mu \mathrm{M}$ indomethacin.

Aluminosilicate glass electrodes were used for extracellular recordings from nodose ganglia neurons. The recordings were amplified (A-M Systems, Model 1800) and filtered (low cutoff, $0.3 \mathrm{kHz}$; high cutoff, $1 \mathrm{kHz}$ ) and then displayed on an oscilloscope (TDS 340, Tektronix) and a model TA240S chart recorder (Gould). The data were stored on digital tape (DTC-59ES, Sony Corporation) for off-line analysis on a Macintosh computer equipped with PHOCIS software.

Mechanical thresholds, or the force generated by the smallest von Frey filament ending (Stoelting) that evoked action potentials, were determined for each nerve fiber. For acid challenges, $500 \mu \mathrm{l}$ of $10 \mathrm{~mm}$ citric acid was administered over $\sim 3 \mathrm{~s}$ at the site of an identified receptive field 
(care was taken not to mechanically disturb the mucosal surface). Electrical stimulation was likewise performed by manipulating a concentric stimulating electrode onto the mucosal site of an identified receptive field. One fiber per animal was recorded. The effects of $3 \mu \mathrm{M}$ ouabain (10 min pre-incubation) on afferent nerve responses were assessed in a nonpaired experimental design.

Data analysis. Results are presented as a mean \pm SEM of $n$ experiments, where $n$ is the number of animals studied. Cough was defined based on visual confirmation of a cough-like respiratory effort, and based on changes in tracheal pressure that produced $a \geq 500 \%$ increase in peak expiratory pressure preceded by an enhanced inspiratory effort. Statistical differences between group means were assessed by ANOVA. $p<0.05$ was considered significant.

\section{Results}

\section{Origin and projections of the} cough receptors

Fast blue injected into the rostral guinea pig trachea and larynx retrogradely labeled neurons in the jugular and nodose ganglia (Fig. $1 A, B$ ). Confirming previous studies (Ricco et al., 1996; Mazzone and Canning, 2002), about half of the labeled jugular ganglia neurons stained positively for substance $\mathrm{P}$ (Fig. $1 \mathrm{~B}$ ). The remaining fast blue-labeled jugular ganglia neurons and all fast blue labeled nodose ganglia neurons were substance P-negative (Fig. $1 B)$. Unilateral recurrent laryngeal nerve (RLN) transection reduced significantly the number of fast blue-labeled neurons in the ipsilateral nodose ganglia but had little effect on the number of traced neurons in the ipsilateral jugular ganglia (Fig. 1C). In contrast, unilateral SLN transection significantly reduced the number of traced neurons in the jugular ganglia without any apparent effect on the number of traced neurons in the nodose ganglia (Fig. 1C).

As shown previously (Canning et al., 2004), cough evoked mechanically or by citric acid applied topically to the tracheal mucosa was abolished by bilateral RLN transection (Fig. 1D,E). SLN transection had no effect on cough (Fig. 1D). Bolus application of capsaicin to the trachea, a selective stimulant of laryngeal and tracheal jugular ganglia neurons (Ricco et al., 1996; Canning et al., 2004), produced modest (if any) effects on respiration, and did not evoke cough (Fig. $1 E$ ). These data and our previous studies (Canning et al., 2004, 2006a) suggest that in the guinea pig trachea and larynx, nodose ganglia-derived afferent nerves regulate cough and project to these airways via the recurrent laryngeal nerves.

\section{Intravital neuronal labeling by FM2-10 in airway wholemount preparations}

FM2-10 brilliantly and selectively labeled a subset of mucosal nerve terminals in living whole mounts of guinea pig trachea and mainstem bronchi (Fig. 2). These structures comprised only a
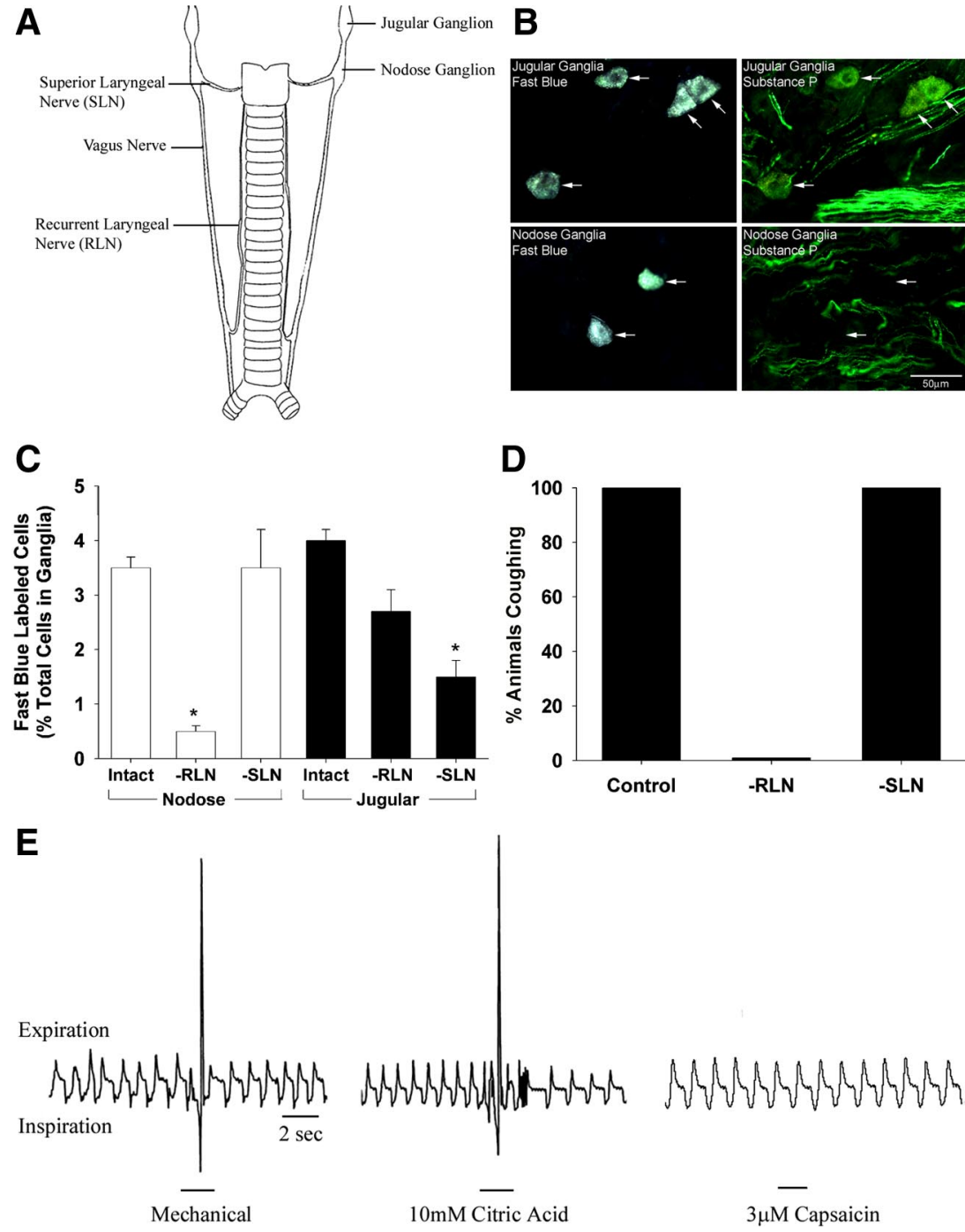

Figure 1. Origin of the sensory nerves that regulate cough evoked from the guinea pig trachea. $A$, Stylized representation of the vagal innervation of the guinea pig trachea and larynx. $\boldsymbol{B}$, Retrograde neuronal tracing from the airways reveals distinct populations of sensory nerve subtypes originating in the jugular or nodose ganglia. Many jugular ganglia neurons (but none of the labeled nodose neurons) stained positive for the neuropeptide substance P (representative of 4 similar experiments, scale bar denotes 50 $\mu \mathrm{m})$. C, Effect of unilateral transection of a recurrent or superior laryngeal nerve (RLN or SLN) on the number of retrogradely traced neurons in the ipsilateral nodose and jugular ganglia $(n=3)$. $\boldsymbol{D}$, Effect of bilateral $\operatorname{RLN}(n=9)$ or $\operatorname{SLN}(n=7)$ transection on cough evoked by mechanical probing of the trachea and larynx in anesthetized guinea pigs. Identical results were obtained in studies of cough evoked by topically applied citric acid ( $10 \mathrm{~mm}$ in a $100 \mu$ l aliquot). $\boldsymbol{E}$, Representative traces showing respiratory responses in anesthetized guinea pigs evoked by stimulation of the tracheal mucosa with either mechanical probing, bolus application of $10 \mathrm{~mm}$ citric acid or superfusion $3 \mu \mathrm{m}$ capsaicin. Mechanical probing and citric acid (stimuli that activate tracheal neurons in both the nodose and jugular ganglia) evoked a cough response (large spikes on the respiratory traces) whereas tracheal capsaicin (a selective stimulant of tracheal neurons originating in the jugular ganglia) produces minimal respiratory effects and no coughing. Traces are representative of more then 10 similar experiments.

fraction of the total nerve density (as revealed by PGP9.5 immunostaining) (Fig 2A), and have complex dendritic arbors that originate from primary axons (also labeled by FM2-10) that project to the mucosa through the underlying smooth muscle layer and terminate adjacent to the tips of the cartilage rings (Fig. 2B). FM2-10-labeled terminals were easily distinguished from the afferent $\mathrm{C}$-fiber terminals containing substance $\mathrm{P}$, which form a characteristically disorganized and dense plexus in the tracheal mucosa (Fig. 2C). The FM2-10 labeled terminals branch extensively along the circumferential axis of the airways and are evenly distributed along the entire length of the trachea (2-4 terminals/tracheal cartilage ring; Fig 2D). These terminals resem- 

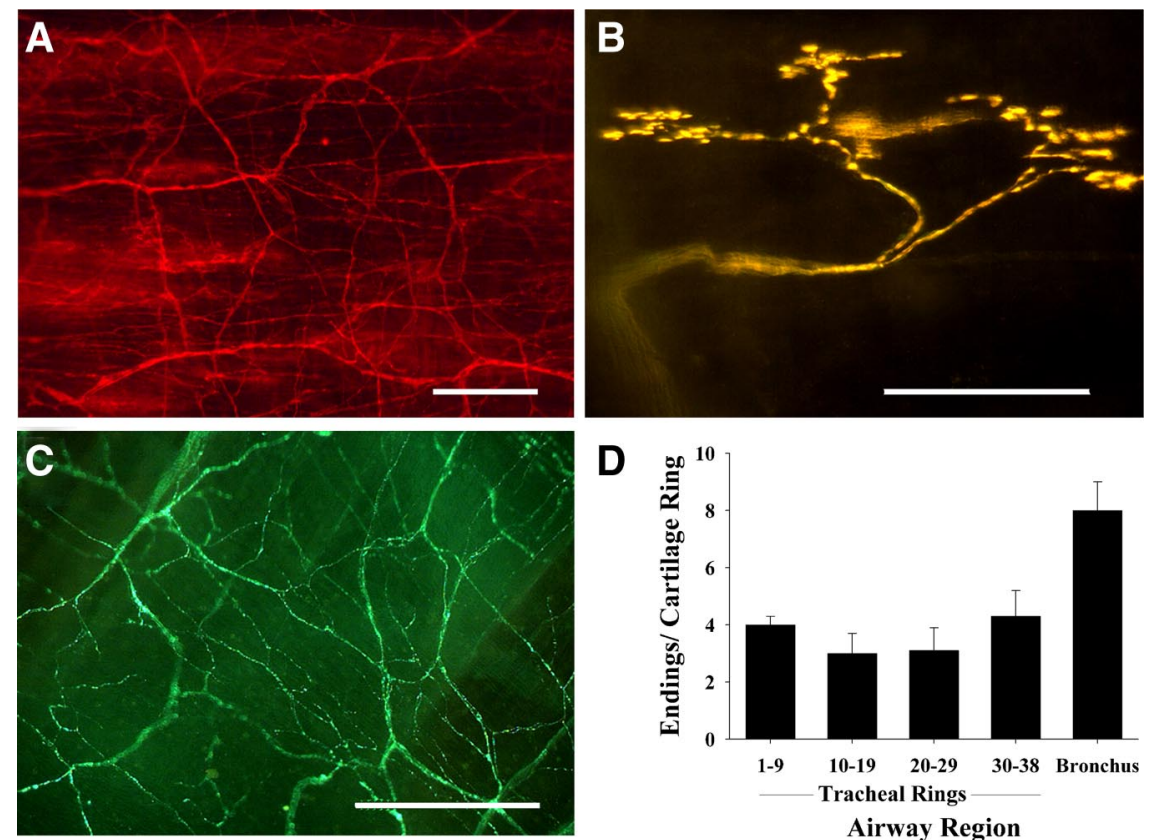

Airway Region

Figure 2. Identification and distribution of nerve terminals in guinea pig tracheal and bronchial wholemounts. A, Immunohistochemical staining for the non-specific neuronal marker protein gene product (PGP) 9.5 reveals dense innervation of the tracheal mucosa. $\boldsymbol{B}$, Intravital staining using the fluorescent styryl dye FM2-10 labels a distinct subset of these nerve fibers. The labeling produced by FM2-10 was persistent (up to $24 \mathrm{~h}$ ). C, Immunohistochemical staining for substance $P$ shows the arrangement of jugular ganglia-derived C-fibers in the trachea. D, Quantitative distribution of FM2-10-labeled nerve terminals in the trachea (from rostral to caudal) and mainstem bronchi $(n=4)$. Scale bars, $50 \mu \mathrm{m}$. The tissues as viewed have their rostral-most edges at the top of each micrograph, which are representative of $4-10$ experiments.

A

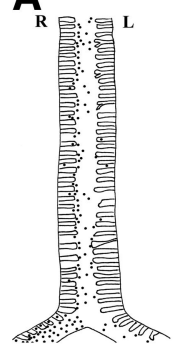

B

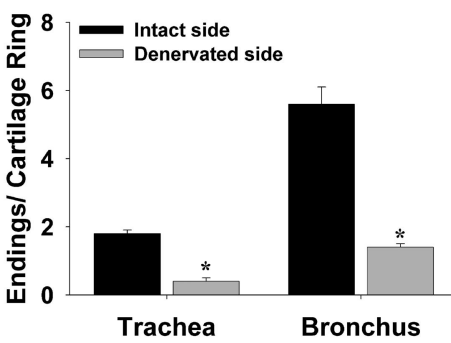

C

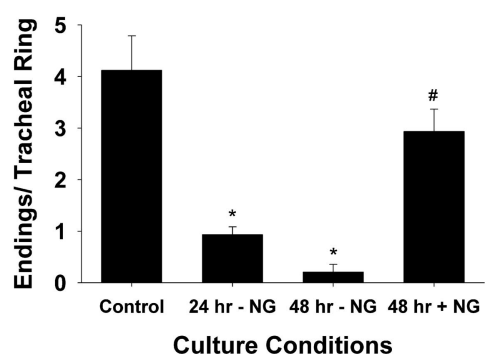

Figure 3. Identification of FM2-10 labeled nerve terminals in the guinea pig airways. $\boldsymbol{A}$, Sketch showing the distribution of FM2-10 labeled nerve terminals (shown as black dots) in the trachea and mainstem bronchi of a guinea pig that had undergone a unilateral (left) vagotomy $7 \mathrm{~d}$ before FM2-10 staining. Note that there are fewer terminals on the denervated side of the airways. $\boldsymbol{B}$, Quantitative assessment of the effects of unilateral vagotomy on the density of FM2-10-labeled nerve endings $(n=3)$. $\boldsymbol{C}$, Effects of organotypic culture of the trachea, with and without the nodose ganglia (NG) and associated vagal nerves, on the number of FM2-10 labeled nerve terminals ( $n=4$ per group). ${ }^{*} p<0.05$ significantly fewer FM2-10 labeled nerve terminals compared with control conditions (i.e., no culture). " $p<0.05$ significantly more FM2-10 labeled nerve terminals compared with $48 \mathrm{~h}$ of culture without the nodose ganglia.

ble those identified as SARs in rabbit lung by Yu et al. (2003), who used antisera to the $\alpha_{3}$ subunit of $\mathrm{Na}^{+}-\mathrm{K}^{+}$-ATPase to label SAR terminals in fixed lung tissue. But these nerve endings are unlikely to be those of SARs, as we find no evidence in electrophysiological studies for SAR terminations in the trachea or bronchi of guinea pigs (Canning et al., 2004). Terminal densities tended to increase around the carina and approximately doubled in the mainstem bronchi (7-8 terminals/bronchial cartilage ring). Labeling did not work in tissue cross sections, as the cut edges of the tissues labeled intensely and nonselectively. Other styryl dyes including FM1-43 and 4-Di-2-ASP (5-50 $\mu \mathrm{M}$ each) produced similar patterns of labeling, but of inferior quality (data not shown).
FM2-10 labeled nerve terminals arise from the nodose ganglia

Unilateral vagotomy (caudal to the superior laryngeal nerve) 7-14 d before staining reduced by about half the number of terminals stained by FM2-10 in the guinea pig trachea and the mainstem bronchi ipsilateral to the cut nerve (Fig. $3 A, B$ ). The loss of FM2-10 labeled terminals occurred along the entire length of the trachea but was confined primarily to the mucosa ipsilateral to the severed vagus nerve (Fig. $3 A$ ). The number of FM2-10 labeled nerve terminals was also reduced in tracheal tissues that were cultured for $24-48 \mathrm{~h}$ in the absence of all extrinsic innervation (Fig. $3 C)$. Terminals that persisted after $48 \mathrm{~h}$ in these cultures showed signs of degeneration and were only faintly labeled by FM2-10. This loss of labeling intensity resulted in a significant $(p<0.05)$ reduction in the number of terminals visualized. Importantly, however, nerve terminal staining was preserved and robust in cultured trachea when the RLNs, vagi and nodose ganglia were left intact (Fig. 3C).

\section{Lack of FM2-10 nerve terminal labeling} or a cough reflex in rats

In rat tracheal wholemounts, FM2-10 labeled a subset of nerve terminals with morphology similar to those labeled in the guinea pig (Fig. $4 A, B$ ). These nerve terminals were again readily differentiated from substance P-containing fibers (Fig. 4C). But the rat tracheae contained 30-40 times fewer FM2-10 labeled terminals than the guinea pig trachea (180-200 terminals/guinea pig trachea versus 3-7 terminals/rat trachea). In the rat, these FM2-10 labeled terminals were found exclusively in the caudal-most segment of the trachea, adjacent to the carina. We and other investigators have reported comparable preliminary results previously (Mazzone and Canning, 2003; Canning et al., 2006a; De Proost et al., 2007).

Interestingly, retrograde neuronal tracing from the airways identified neurons in the vagal sensory ganglia of rats that had a wide range of somal diameters (range $14-53 \mu \mathrm{m}$, median $\sim 31 \mu \mathrm{m})$. However, regardless of somal size, the majority $(>90 \%)$ of fast blue-labeled cells in rat vagal ganglia stained positively for TRPV1, a marker for nociceptive-type sensory neurons (data not shown). Previous studies have confirmed that guinea pig cough receptors do not express TRPV1 (Ricco et al., 1996; Canning et al., 2004; Kwong et al., 2008).

Consistent with the paucity of FM2-10 labeled nerve terminals in the rat trachea and the evidence that these terminals in guinea pigs correspond to the peripheral terminals of cough receptors, anesthetized rats failed to cough in response to any of the stimuli that readily evoked cough in anesthetized guinea pigs (Fig. 4D). 
Rather, these stimuli produced a sustained apnea lasting the duration of the stimulus. Apnea also followed tracheal application of capsaicin in rats (data not shown) and in guinea pigs (Canning et al., 2004).

\section{Cough receptors terminate in the subepithelial extracellular matrix} The studies described above implicate vagal afferents arising from the nodose ganglia in cough and suggest that their peripheral terminals are selectively and brilliantly labeled by FM2-10. We further characterized the terminations of the cough receptors with intravital imaging. FM2-10 labeled nerve endings in the tracheal and bronchial mucosa were not associated with the epithelium. In fact, visualization (but not staining) was difficult unless the epithelium was removed (see supplemental Fig. 1, available at www.jneurosci.org as supplemental material). Terminals were also clearly separate from the smooth muscle layer. Using water-immersion microscopy and interchanging between fluorescent and bright field light sources, it was apparent that the cough receptor terminals were confined to the extracellular matrix between the smooth muscle layer and the epithelium (Fig. 5). These observations are consistent with our previous reports that coughing in anesthetized guinea pigs is unaffected by bronchospasm, airway smooth muscle contraction or epithelium removal (Canning et al., 2004, 2006a).

The terminal boutons of the cough receptors were adhered to the adventitial surface of the largely acellular matrix, with extensive branching in a circumferential axis, parallel to the underlying smooth muscle bundles. When viewed in real time, punctate mechanical probing of the mucosa [which we have shown previously initiates coughing (Canning et al., 2004)] profoundly and unevenly distorted the shape and orientation of the terminal arbors (data not shown). We had also shown previously that airway smooth muscle contraction neither activates the cough receptors in vitro nor initiates coughing in vivo (Canning et al., 2004, 2006). We provide additional evidence that cough receptor excitability is largely unaffected by smooth muscle contraction in the present study, as citric acid ( $0.001-2 \mathrm{M})$ evoked $7 \pm 1$ versus $8 \pm 1$ coughs in control preparations and in preparations in which the trachealis was contracted (to a near maximum) with $3 \mu \mathrm{M}$ substance $\mathrm{P}$, respectively $(n=6$ each; $p>0.1)$. Tracheal challenge with substance $\mathrm{P}$ did not evoke cough or produce any changes in respiratory pattern in these studies.

Expression of a sodium pump isozyme by the cough receptors FM2-10 labeling of nerve terminals in living wholemounts of the tracheal mucosa and the intensity of terminal labeling was indistinguishable when labeling was conducted in the absence or presence of extracellular calcium or with coincident electrical stimulation. Electrical and chemical stimulation also failed to reverse FM2-10 labeling and did not induce labeling of any additional (previously unlabeled) structures. These data argue against a vesicular dependent labeling process as has been described in other systems and with other styryl dyes. FM2-10 labeling of the nerve terminals by cell entry through voltage-gated sodium or potassium channels, TRPV1 or P2X receptors, or mechanotransducing channels including $\mathrm{ENaC}$ also seems unlikely, as pretreating guinea pig tracheae with the cation channel blockers/ligands TTX, 4-AP, PPADS, capsazepine, gadolinium, or amiloride was without effect on the number of labeled nerve terminals or the intensity of FM2-10 staining ( $n=3-4$ each; data not shown). FM2-10 labeling was, however, significantly reduced when staining was conducted at room temperature and abolished at $4^{\circ} \mathrm{C}$ $\left(3.7 \pm 0.6,1.1 \pm 0.3\right.$ and $0 \pm 0$ terminals/tracheal ring at $37^{\circ} \mathrm{C}$, room temperature and $4^{\circ} \mathrm{C}$, respectively; $p<0.05$ ), suggesting a $\mathrm{Ca}^{2+}$-independent but metabolically active labeling process that is unlikely to involve permeation through open cation channels.

In contrast to the interventions described above, the $\mathrm{Na}^{+}$$\mathrm{K}^{+}$-ATPase inhibitor ouabain dose-dependently reduced the intensity of FM2-10 terminal labeling, ultimately resulting in significantly fewer visible terminals in the wholemounts (Fig. 6). The concentrations of ouabain used suggested the involvement of an isozyme of $\mathrm{Na}^{+}-\mathrm{K}^{+}$-ATPase with high ouabain sensitivity and/or high basal activity in the terminals during FM2-10 labeling. Indeed, in tracheal whole mounts, nerve terminals that were morphologically similar to the terminals labeled by FM2-10 were labeled immunohistochemically for an isozyme of $\mathrm{Na}^{+}-\mathrm{K}^{+}$ATPase containing the $\alpha_{3}$ subunit (double labeling was not possible as FM2-10 labeling does not persist in fixed tissues). The location and density of the terminals expressing the $\alpha_{3}$ subunit and FM2-10-labeled nerve terminals were also comparable. In $60-\mu \mathrm{m}$-thick cross sections of the trachea, $\alpha_{3}$ subunit immuno- 

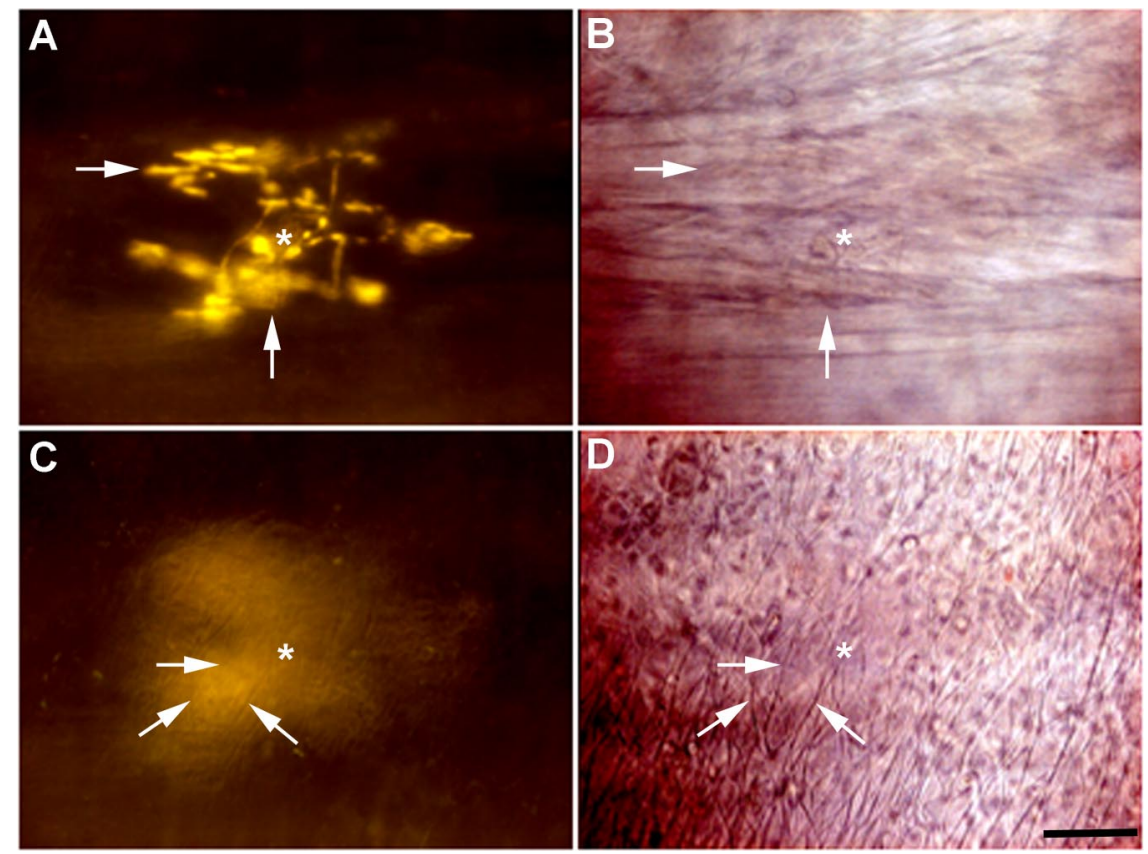

Figure 5. Cough receptors terminate in the extracellular matrix between the epithelium and smooth muscle layers of the tracheal and bronchial mucosa. $\boldsymbol{A}-\boldsymbol{D}$, Cough receptors were labeled intravitally with FM2-10 and following epithelium removal, were visualized through water-immersion optics using epifluorescent $(\boldsymbol{A}$ and $\boldsymbol{C}$ ) or brightfield illumination $(\boldsymbol{B}$ and $\boldsymbol{D})$. Terminations assume a stereotypical circumferential arbor ( $\boldsymbol{A}$; see also Figs. 2 and 6 ), arranged parallel but clearly separate from the underlying smooth muscle bundles $(\boldsymbol{B})$, which are also circumferentially arranged in the airway wall, adherent to the tips of the cartilage rings. The center and branching portions of the terminals are marked by an asterisk and by large arrows, respectively, in $\boldsymbol{A}$ and $\boldsymbol{B}$. Lifting the plane of focus to the first visible components of the subepithelial mucosa reveals the intricate structure of an extracellular matrix with interconnected fibers extending longitudinally on the luminal side of the matrix (identified with small arrows in C and D), and circumferentially (not visible) along the adventitial side of the matrix, apposed to but dissociated from the underlying smooth muscle. The cough receptor terminals clearly failed to penetrate to the luminal side of the matrix and were adherent to its adventitial surface ( $\boldsymbol{C}$ and $\boldsymbol{D}$ ). Rostral-caudal axis of the airways is arranged vertically in these photomicrographs, which are representative of 6 separate experiments.

staining confirmed the subepithelial location of the terminals. Double labeling also showed an obvious distinction between $\alpha_{3}$ subunit- and substance P-labeled fibers. The perikarya of retrogradely labeled nodose ganglia neurons projecting to the trachea also label for the $\alpha_{3}$ subunit of the sodium pump (Mazzone and McGovern, 2008).

As mentioned above, FM2-10 labeling of cough receptor terminals was largely prevented when labeling was attempted at room temperature or at $4^{\circ} \mathrm{C}$. But when tracheal wholemounts were incubated with FM2-10 at room temperature and then rewarmed by washing at $37^{\circ} \mathrm{C}$ in the absence of excess dye (excess dye was first washed away thoroughly at room temperature), labeling of nerve terminals with FM2-10 was nearly restored (Fig. $6 F)$. Ouabain mimicked the effects of cooling, reducing both the number and intensity of labeled terminals. Ouabain also hastened the reversal of FM2-10 labeling (see supplemental Fig. 2, available at www.jneurosci.org as supplemental material). In 2 paired experiments, nerve terminal fluorescence intensity was well preserved over the initial $5 \mathrm{~min}$ after excess dye washout (97 and $76 \%$ of fluorescence intensity at time $=0$ after wash) but was greatly diminished when $10 \mu \mathrm{m}$ ouabain was included in the wash buffer ( 55 and $56 \%$ of fluorescence intensity at time $=0$ after wash).

Evidence that a $\mathrm{Na}^{+}-\mathrm{K}^{+}$-ATPase isozyme selectively regulates cough receptor excitability

The $\alpha_{3}$ subunit containing isozyme of the sodium pump may play an important role in regulating cough receptor excitability (Fig.
7). Topical application of citric acid or mechanical probing of the mucosa evoked transient high-frequency bursts of action potentials in all cough receptors studied. In the presence of ouabain, however, there was a significant reduction in the number of acid-evoked action potentials and an increase in the mechanical force needed to activate the fibers (Fig. $7 B, C$ ). The effects of ouabain on citric acid-evoked responses were partially reversed with washout, which also completely restored their mechanical sensitivity.

Using a stimulus voltage that was twice threshold for activation, electrical stimulation of identified cough receptor terminals at increasing stimulus frequencies resulted in a frequency-dependent increase in the number of recorded action potentials (Fig. 7D). Cough receptors reliably conduct action potentials up to 32 $\mathrm{Hz}$ for $10 \mathrm{~s}$ continuously with few action potential failures. But in the presence of ouabain, the percentage of action potential failures was increased substantially, especially at high frequencies (Fig. 7D). Ouabain, at the doses studied, did not activate these nerve endings or prevent entirely their activation by chemical (acid), mechanical or electrical stimulation, arguing against a complete loss of $\mathrm{Na}^{+}$gradient or depolarization block.

In anesthetized guinea pigs, tracheal perfusion with $3 \mu \mathrm{M}$ ouabain greatly reduced the number of coughs evoked by citric acid and abolished cough evoked by mechanical probing of the trachea (Fig. 8). Cooling the tracheal perfusate to $4^{\circ} \mathrm{C}$ mimicked the effects of ouabain on citric acid evoked coughing (Fig. 8A). Electrically stimulating the trachea (at a supramaximal stimulus intensity and duration) evoked coughing in a frequency-dependent manner (Fig. $8 \mathrm{~B}$ ). Relatively high stimulation frequencies $(8-16 \mathrm{~Hz})$ were required to reliably and consistently evoke cough. In the presence of ouabain, the stimulation frequency required to evoke cough was greatly increased (Fig. $8 \mathrm{~B}$ ). Thus, whereas all vehicle-treated animals coughed during 16 $\mathrm{Hz}$ and $32 \mathrm{~Hz}$ stimulation, only 1 of 5 animals treated with ouabain coughed at $16 \mathrm{~Hz}$, and 4 of 5 coughed at $32 \mathrm{~Hz}$. Tracheal application of ouabain alone did not alter baseline respiratory activity or produce any noticeable reflex responses. Moreover, ouabain was without effect on the respiratory slowing and apneas that accompanied the citric acid challenges, an effect likely mediated by coincident activation of tracheal and laryngeal C-fibers (Canning et al., 2006a).

Low doses of intravenous ouabain also selectively inhibited coughing. In anesthetized guinea pigs, intravenous ouabain at doses $<0.1 \mathrm{mg} / \mathrm{kg}$ had no effect on heart rate, blood pressure or respiratory rate, which at baseline averaged $245 \pm 5$ beats $/ \mathrm{min}$, $43 \pm 3 \mathrm{mmHg}$ and $67 \pm 8$ breaths/min, respectively $(n=7)$. But $0.03 \mathrm{mg} / \mathrm{kg}$ ouabain nearly abolished citric acid evoked coughing (citric acid evoked $11 \pm 1$ coughs following vehicle administration but only $3 \pm 1$ coughs following $0.03 \mathrm{mg} / \mathrm{kg}$, i.v. ouabain; $n=5-6 p<0.05)$. Higher doses of ouabain dramati- 
cally altered heart rate, respiratory rate and blood pressure, initially increasing respiratory rate, but eventually decreasing all 3 parameters (data not shown; $n=7$ ).

\section{Discussion}

We showed previously that cough evoked from the trachea and larynx of anesthetized guinea pigs is initiated by activating acidsensitive A $\delta$ mechanoreceptors (Canning et al., 2004). These vagal afferents are differentiated from intrapulmonary mechanoreceptors (SARs and RARs) and bronchopulmonary C-fibers by their terminal location, conduction velocity, sensitivity to punctate mechanical stimulation and insensitivity to tissue stretch, intraluminal pressure changes, capsaicin, bradykinin, ATP, adenosine, and 5-HT. We used retrograde neuronal tracing and immunohistochemistry combined with functional studies of cough with and without nerve transections to show that the cough receptors arise exclusively from the nodose ganglia. These experiments also helped link the FM2-10 labeled nerve terminals to the nodose ganglia and to the cough receptors.

Cough receptors are insensitive to airway smooth muscle contraction but are vigorously activated by light touch or acid applied topically to their receptive fields (Canning et al., 2004). Our discovery that FM2-10 selectively and intravitally labels these terminals may reveal a structural basis for these functional characteristics. We found that cough receptors were not embedded in the underlying smooth muscle and did not penetrate the epithelium or the mucosal side of the extracellular matrix. Their adherence to the subepithelial matrix conjures images of a spider poised on a web, sensing physical disturbances signaled through the structure of the matrix. The matrix appears uncoupled from the underlying smooth muscle, as muscle contraction does not activate the cough receptors or alter their excitability. Epithelial cells (including neuroendocrine cells) and epithelial-derived signaling molecules also appear to play no role in transducing cough receptor reflexes [based on the physical dissociation of the cough receptors from the epithelium, the lack of effect of epithelium removal on cough receptor activation and evoked cough, and cough receptor insensitivity to 5-HT, ATP, 15-HETE, and adenosine (Canning et al., 2006a; Carr et al., 2001; Chou et al.; 2008; Hwang et al., 2000; Kwong et al., 2008; Mazzone and Canning, 2002; Undem et al., 2004)].

The circumferential arborization of the cough receptors likely reflects their adherence to components of the matrix deposited along a circumferential axis. Their terminal structures contrast with that of C-fibers, which show no discernable organization, penetrate the epithelium and have extensive arbors throughout the air- way wall (present study; Baluk and Gabella, 1991; Mazzone and McGovern, 2006; Watanabe et al., 2006). These differing terminal attributes may be related to a differential expression of integrins that adhere to specific components of the extracellular matrix (Guan et al., 2003). It will be interesting to re-evaluate this arrangement following mucosal injuries such as those associated with asthma or chronic obstructive pulmonary disease (COPD), which produce extensive remodeling of the subepithelial extracellular matrix (Jeffery, 2001). These structural attributes may also lead to experiments that better describe the peculiar mechanical properties of these afferent nerves, including their insensitivity to changes in intraluminal pressure despite exquisite sensitivity to punctate mechanical stimulation, which is unaffected by the mechanosensing channel-blocker gadolinium (Carr et al., 2001; Canning et al., 2004). 

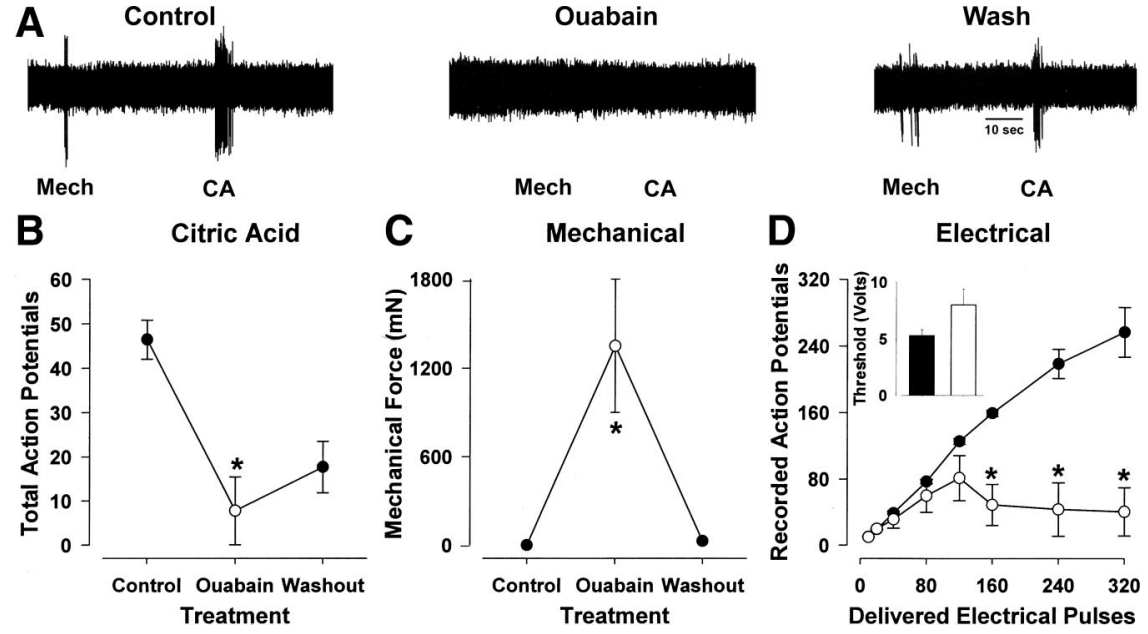

Figure 7. Effect of $3 \mu \mathrm{m}$ ouabain on the in vitro electrophysiological properties of tracheal cough receptors. $A-C$, Representative recordings $(\boldsymbol{A})$ and mean data $(\boldsymbol{B}, \boldsymbol{C})$ showing that a $10 \mathrm{~min}$ ouabain pretreatment reduced the number of action potentials evoked by $10 \mathrm{~mm}$ citric acid $(\boldsymbol{B})$, an effect that was partially restored after washing. $\boldsymbol{C}$, Ouabain also reversibly increased the mechanical threshold required to activate nodose fibers. $\boldsymbol{D}$, In the absence of ouabain, electrical impulses delivered over $10 \mathrm{~s}$ at increasing frequencies to the receptive field of the cough receptors reliably evoked action potentials with only a few failures up to frequencies as high as $32 \mathrm{~Hz}$ (closed circles). In the presence of ouabain, the number of recorded action potentials was significantly lower compared to controls at frequencies $>16 \mathrm{~Hz}$. This was accompanied by a small, but statistically insignificant, elevation in the voltage threshold for fiber activation (inset). Data are expressed as the mean $\pm \operatorname{SEM}(n=4) .{ }^{*} p<0.05$, significantly different from control.
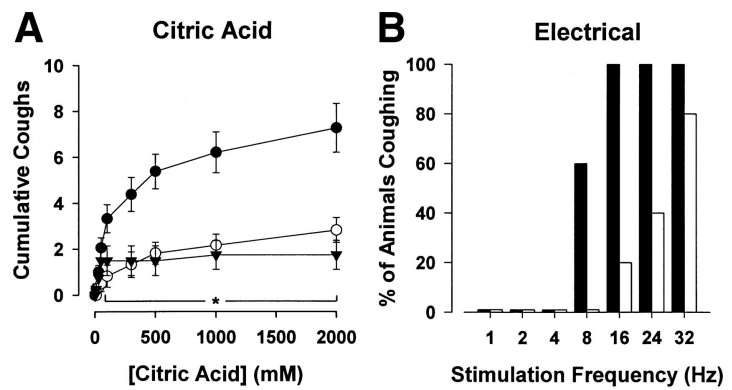

Figure 8. Effect of $3 \mu \mathrm{m}$ ouabain on cough in urethane-anesthetized guinea pigs. $A$, Bolus application of citric acid (1-2000 mM) onto the tracheal mucosa evoked a cumulative increase in the number of coughs. The number of citric acid-evoked coughs was significantly $(p<0.05)$ reduced in the presence of ouabain (open circles) and by cooling the tracheal perfusate to $4^{\circ} \mathrm{C}$ (triangles). Conversely, ouabain and tracheal cooling had no effect on citric acid evoked respiratory slowing, a reflex response that is likely mediated by jugular ganglia-derived nociceptors (peak percentage decreases in respiratory rate evoked by $1 \mathrm{~m}$ citric acid challenge averaged $51 \pm 8 \%, 49 \pm 10 \%$ and $45 \pm 7 \%$ in control preparations and in preparations treated with ouabain or tracheally perfused with $4^{\circ} \mathrm{C}$ Krebs buffer, respectively; $\left.n=6-8\right)$. B, Ouabain also completely abolished mechanically evoked cough (5/5 anesthetized guinea pigs treated with vehicle and $0 / 5$ anesthetized guinea pigs treated with ouabain coughed in response to mechanical probing of the tracheal mucusa) and produced an increase in the frequency of electrical stimulation (at supramaximal voltages) required to evoke cough. Data are expressed as the mean \pm SEM ( $n=5-8$ experiments). ${ }^{*} p<0.05$, significantly different from control.

\section{Mechanisms underlying the interaction of FM2-10}

\section{with the guinea pig cough receptor}

Unlike styryl dye labeling of other cells (Betz et al., 1992; Ryan et al., 1993; Ribchester et al., 1994; Kirchgessner et al., 1996; Hay and Hasser, 1998; Kay et al., 1999; Gale et al., 2001) we found that FM2-10 staining of cough receptors did not require and was not reversed by nerve stimulation. Although labeling was prevented by cooling (suggesting an active process), it was unaffected by removing extracellular calcium, arguing against calciumdependent vesicular transport. Indeed, it is unknown whether these mechanically sensitive nerve terminals have the synaptic proteins, calcium channels and vesicles typically found in nerve endings labeled by styryl dyes (Süudhof, 2008). Styryl dyes can also act as permeant blockers of mechanotransduction in cochlear hair cells and can label cells expressing TRPV1 or $\mathrm{P}_{2} \mathrm{X}_{2}$ receptors following activation and movement through the open channels (Nishikawa and Sasaki, 1996; Gale et al., 2001; Meyers et al., 2003). We found that FM2-10 labeling of cough receptors was unaffected by drugs that target these channels, including capsazepine (TRPV1), PPADS (P2X $\left.\mathrm{X}_{2 / 3}\right)$ and gadolinium (mechanotransduction channels). Cough receptor mechanotransduction is also unaffected by FM1-43 or FM2-10 (S. Mazzone and M. Kollarik, unpublished observations). Thus, if FM2-10 permeates cough receptor ion channels, it does so in a way that does not alter cation permeation or normal channel function.

We believe that FM2-10 labels the terminals of the cough receptors because of their expression of sodium pumps using the $\alpha_{3}$ subunit. Consistent with this hypothesis, labeling was prevented by low concentrations of ouabain or by cooling the tissues during FM2-10 incubation. Partitioning of FM2-10 in cough receptor membranes seems insufficient to produce the intense labeling. Rather, our data suggest that the sodium pumps have to be active for the fluorescence to become visible. Tissues incubated at low temperatures in the presence of FM210 , followed by removal of excess dye, displayed little or no labeling without rewarming. For reasons that remain obscure, something about the movement of $\mathrm{Na}^{+}$and/or $\mathrm{K}^{+}$, or the charge movement associated with pump activity, may be necessary for FM2-10 fluorescence in cough receptor terminals, and something about the charge regulation in these specific nerve terminals may promote their selective labeling by FM210. Styryl dyes are known to display voltage sensitivity and responsiveness to charge movements evoked by pump activity (Bühler et al., 1991; Clarke et al., 1992, 1995; Fedosova et al., 1995; Pedersen et al., 2002).

Additional evidence suggests that FM2-10 labeling of the cough receptors is due to the unique expression of a sodium pump isozyme. Immunohistochemical analyses confirm the expression of the $\alpha_{3}$ subunit in the cough receptor terminals and perikarya (present study; Mazzone and McGovern, 2006; Mazzone and McGovern, 2008). We have sequenced the guinea pig $\alpha_{3}$ subunit gene and quantified its expression in various tissues and organs. As expected, we found no $\alpha_{3}$ gene transcripts in guinea pig airway or lung cDNA libraries but high expression in the nodose ganglia. We also have data to suggest that intravital labeling of the cough receptors is not necessarily due to a high density of expression of this sodium pump isozyme but rather, due to an apparently high basal activity. Using rhodamine labeled ouabain to visualize sodium pumps in the guinea pig trachea, we found that at concentrations evoking near maximum contractions of the underlying trachealis, fluorescent ouabain failed to differentially label cough receptors (suggesting that pump activity and not number accounts for the selective labeling of the terminals by FM2-10). 
The role of $\alpha_{3} \mathrm{Na}^{+} / \mathrm{K}^{+}$ATPase in cough receptor function Sodium pump isozymes can be differentiated by their affinity for ouabain (Maixent et al., 1987; Berrebi-Bertrand et al., 1991; Berrebi-Bertrand and Maixent, 1994; Gao et al., 1995; Juhaszova and Blaustein, 1997; Dobretsov et al., 1999; Lingrel et al., 2003). The apparent potency of ouabain for preventing FM2-10 labeling was consistent with the expression of an $\alpha_{3}$-containing isozyme of $\mathrm{Na}^{+} / \mathrm{K}^{+}$ATPase in tracheal cough receptors. This subunit is reported to have a high affinity for ATP and a low affinity for $\mathrm{Na}^{+}$ (Jewell and Lingrel, 1991; Maixent and Berrebi-Bertrand, 1993; Munzer et al., 1994; Crambert et al., 2000). Accordingly, sodium pumps using the $\alpha_{3}$ subunit may be more adept at functioning when ATP concentrations are low and intracellular $\mathrm{Na}^{+}$concentrations are high, as in highly active cells. In addition to the cough receptors, other mechanosensors including muscle spindle receptors and intrapulmonary SARs also express the $\alpha_{3}$-containing $\mathrm{Na}^{+} / \mathrm{K}^{+}$ATPase isozyme. This suggests an important role for this isozyme in mechanoreceptor function or signaling, perhaps by regulating high-frequency action potential patterning (Dobretsov et al., 2003; Yu et al., 2003; Mazzone and McGovern, 2006; Mazzone et al., 2006). A recent study of auditory neurons suggests that the $\alpha_{3}$ containing isozyme may also be critical for their continuous, repetitive high-frequency activation (Kim et al., 2007). We have noted here and elsewhere the need for sustained high-frequency activation of the cough receptors when encoding coughs (Canning, 2007). Given their proximity to the epithelium and the possibility that environmental (e.g., cold air) and pathological (e.g., aspiration, allergen challenge, infection) conditions may prompt the epithelium to generate large changes in local extracellular $\mathrm{Na}^{+}, \mathrm{K}^{+}, \mathrm{Cl}-$ and/or $\mathrm{H}+$ concentrations, the capacity to quickly and effectively regulate $\mathrm{Na}^{+}$and $\mathrm{K}^{+}$gradients at the cough receptor terminals may be critical. These nerve terminals also express a $\mathrm{Na}^{+}-\mathrm{K}^{+}-2 \mathrm{Cl}$-cotransporter (NKCC1), and are exquisitely sensitive to changes in local $\mathrm{Cl}$-concentrations (Canning et al., 2006a; Mazzone and McGovern, 2006).

We found that an $\alpha_{3}$-selective concentration of ouabain decreased cough receptor excitability and reduced cough evoked by mechanical, chemical and electrical stimuli in anesthetized guinea pigs, without affecting responses dependent upon cells expressing other $\mathrm{Na}^{+}-\mathrm{K}^{+}$ATPase isozymes. Intravenous ouabain also nearly abolished coughing at doses that failed to alter cardiovascular function or respiratory rate (largely SARdependent, which have been found to express the $\alpha_{3}$ subunit; Yu et al., 2003). Although definitive evidence awaits more selective inhibitors, we speculate that the $\alpha_{3}$ containing sodium pump is critical to the high-frequency activation required to encode coughing. Future studies may include clinical, pharmacological and gene silencing approaches rather than transgenics. The homozygous $\alpha_{3}$ knockout is a lethal genotype (Moseley et al., 2007), and mice like rats may not have a cough reflex (present study; Belvisi and Bolser, 2002). There is, however, a human disease associated with a mutation of the $\alpha_{3}$ subunit gene (de Carvalho et al., 2004). A clinical assessment of the cough reflex in a cohort of these patients is planned. Interestingly, one member of this cohort died of aspiration pneumonia, a prominent risk among patients with a compromised cough reflex (Smith Hammond and Goldstein, 2006; McKeon et al., 2007).

\section{Conclusions}

We have described the terminal structure of cough receptors and their origin in the nodose ganglia. These studies were made possible by the selective labeling of these terminals in living whole mounts by FM2-10. In characterizing the basis for this labeling, we identified the unique expression of a sodium pump isozyme by the cough receptors. This isozyme may play an essential role in regulating cough receptor excitability. These results may predict a selective and rational approach to cough therapy, and may help further define the mechanosensing properties of these and other mechanosensitive afferent nerves.

\section{References}

Baluk P, Gabella G (1991) Afferent nerve endings in the tracheal muscle of guinea-pigs and rats. Anat Embryol 183:81-87.

Belvisi MG, Bolser DC (2002) Summary: animal models for cough. Pulm Pharmacol Ther 15:249-250.

Berrebi-Bertrand I, Maixent JM (1994) Immunodetection and enzymatic characterization of the alpha 3-isoform of Na,K-ATPase in dog heart. FEBS Lett 348:55-60.

Berrebi-Bertrand I, Maixent JM, Guede FG, Gerbi A, Charlemagne D, Lelievre LG (1991) Two functional $\mathrm{Na}+/ \mathrm{K}+$-ATPase isoforms in the left ventricle of guinea pig heart. Eur J Biochem 196:129-133.

Betz WJ, Mao F, Bewick GS (1992) Activity-dependent fluorescent staining and destaining of living vertebrate motor nerve terminals. J Neurosci 12:363-375.

Bühler R, Stürmer W, Apell HJ, Läuger P (1991) Charge translocation by the $\mathrm{Na}, \mathrm{K}$-pump: I. Kinetics of local field changes studied by time-resolved fluorescence measurements. J Membr Biol 121:141-161.

Canning BJ (2007) Encoding of the cough reflex. Pulm Pharmacol Ther 20:396-401.

Canning BJ, Mazzone SB, Meeker SN, Mori N, Reynolds SM, Undem BJ (2004) Identification of the tracheal and laryngeal afferent neurones mediating cough in anaesthetised guinea-pigs. J Physiol 557:543-558.

Canning BJ, Farmer DG, Mori N (2006a) Mechanistic studies of acidevoked coughing in anesthetized guinea pigs. Am J Physiol Regul Integr Comp Physiol 291:R454-R463.

Canning BJ, Mori N, Mazzone SB (2006b) Vagal afferent nerves regulating the cough reflex. Respir Physiol Neurobiol 152:223-242.

Canning BJ, Undem BJ, Karakousis PC, Dey RD (1996) Effects of organotypic culture on parasympathetic innervation of guinea pig trachealis. Am J Physiol 271:L698-L706.

Carr MJ, Gover TD, Weinreich D, Undem BJ (2001) Inhibition of mechanical activation of guinea-pig airway afferent neurons by amiloride analogues. Br J Pharmacol 133:1255-1262.

Chou YL, Scarupa MD, Mori N, Canning BJ (2008) Differential effects of airway afferent nerve subtypes on cough and respiration in anesthetized guinea pigs. Am J Physiol Regul Integr Comp Physiol 295:R1572-R1584.

Clarke RJ, Schrimpf P, Schöneich M (1992) Spectroscopic investigations of the potential-sensitive membrane probe RH421. Biochim Biophys Acta 1112:142-152.

Clarke RJ, Zouni A, Holzwarth JF (1995) Voltage sensitivity of the fluorescent probe RH421 in a model membrane system. Biophys J 68:1406-1415.

Crambert G, Hasler U, Beggah AT, Yu C, Modyanov NN, Horisberger JD, Lelièvre L, Geering K (2000) Transport and pharmacological properties of nine different human $\mathrm{Na}$, K-ATPase isozymes. J Biol Chem 275:1976-1986.

de Carvalho AP, Sweadner KJ, Penniston JT, Zaremba J, Liu L, Caton M, Linazasoro G, Borg M, Tijssen MA, Bressman SB, Dobyns WB, Brashear A, Ozelius LJ (2004) Mutations in the $\mathrm{Na}+/ \mathrm{K}+$-ATPase alpha3 gene ATP1A3 are associated with rapid-onset dystonia parkinsonism. Neuron 43:169-175.

De Proost I, Pintelon I, Brouns I, Timmermans JP, Adriaensen D (2007) Selective visualisation of sensory receptors in the smooth muscle layer of ex-vivo airway whole-mounts by styryl pyridinium dyes. Cell Tissue Res 329:421-431.

Dobretsov M, Hastings SL, Stimers JR (1999) Functional Na $+/ \mathrm{K}+$ pump in rat dorsal root ganglia neurons. Neuroscience 93:723-729.

Dobretsov M, Hastings SL, Sims TJ, Stimers JR, Romanovsky D (2003) Stretch receptor-associated expression of alpha 3 isoform of the $\mathrm{Na}+$, $\mathrm{K}+$-ATPase in rat peripheral nervous system. Neuroscience 116:10691080.

Fedosova NU, Cornelius F, Klodos I (1995) Fluorescent styryl dyes as probes for $\mathrm{Na}, \mathrm{K}$-ATPase reaction mechanism: significance of the charge of the hydrophilic moiety of RH dyes. Biochemistry 34:16806-16814.

Gale JE, Marcotti W, Kennedy HJ, Kros CJ, Richardson GP (2001) FM1-43 
dye behaves as a permeant blocker of the hair-cell mechanotransducer channel. J Neurosci 21:7013-7025.

Gao J, Mathias RT, Cohen IS, Baldo GJ (1995) Two functionally different $\mathrm{Na} / \mathrm{K}$ pumps in cardiac ventricular myocytes. J Gen Physiol 106:9951030.

Guan W, Puthenveedu MA, Condic ML (2003) Sensory neuron subtypes have unique substratum preference and receptor expression before target innervation. J Neurosci 23:1781-1791.

Hay M, Hasser EM (1998) Measurement of synaptic vesicle exocytosis in aortic baroreceptor neurons. Am J Physiol 275:H710-H716.

Hwang SW, Cho H, Kwak J, Lee SY, Kang CJ, Jung J, Cho S, Min KH, Suh YG, Kim D, Oh U (2000) Direct activation of capsaicin receptors by products of lipoxygenases: endogenous capsaicin-like substances. Proc Natl Acad Sci U S A 97:6155-6160.

Irwin RS, Baumann MH, Bolser DC, Boulet LP, Braman SS, Brightling CE, Brown KK, Canning BJ, Chang AB, Dicpinigaitis PV, Eccles R, Glomb WB, Goldstein LB, Graham LM, Hargreave FE, Kvale PA, Lewis SZ, McCool FD, McCrory DC, Prakash UB, et al. (2006) Diagnosis and management of cough executive summary: ACCP evidence-based clinical practice guidelines. Chest 129[1 Suppl]:1S-23S.

Jeffery PK (2001) Remodeling in asthma and chronic obstructive lung disease. Am J Respir Crit Care Med 164:S28-S38.

Jewell EA, Lingrel JB (1991) Comparison of the substrate dependence properties of the rat $\mathrm{Na}$, K-ATPase $\alpha 1, \alpha 2$ and $\alpha 3$ isoforms expressed in HeLa cells. J Biol Chem 266:16925-16930.

Juhaszova M, Blaustein MP (1997) Na+ pump low and high ouabain affinity alpha subunit isoforms are differently distributed in cells. Proc Natl Acad Sci U S A 94:1800-1805.

Kay AR, Alfonso A, Alford S, Cline HT, Holgado AM, Sakmann B, Snitsarev VA, Stricker TP, Takahashi M, Wu LG (1999) Imaging synaptic activity in intact brain and slices with FM1-43 in C. elegans, lamprey, and rat. Neuron 24:809-817.

Kim JH, Sizov I, Dobretsov M, von Gersdorff H (2007) Presynaptic Ca2+ buffers control the strength of a fast post-tetanic hyperpolarization mediated by the alpha3 $\mathrm{Na}(+) / \mathrm{K}(+)$-ATPase. Nat Neurosci 10:196-205.

Kirchgessner AL, Liu MT, Gershon MD (1996) In situ identification and visualization of neurons that mediate enteric and enteropancreatic reflexes. J Comp Neurol 371:270-286.

Kwong K, Carr MJ, Gibbard A, Savage TJ, Singh K, Jing J, Meeker S, Undem BJ (2008) Voltage-gated sodium channels in nociceptive versus nonnociceptive nodose vagal sensory neurons innervating guinea pig lungs. J Physiol 586:1321-1336.

Lingrel J, Moseley A, Dostanic I, Cougnon M, He S, James P, Woo A, O'Connor K, Neumann J (2003) Functional roles of the alpha isoforms of the Na,K-ATPase. Ann N Y Acad Sci 986:354-359.

Maixent JM, Berrebi-Bertrand I (1993) Turnover rates of the canine cardiac Na,K-ATPase. FEBS Lett 330:297-301.

Maixent JM, Charlemagne D, de la Chapelle B, Lelievre LG (1987) Two $\mathrm{Na}, \mathrm{K}-\mathrm{ATP}$ ase isoenzymes in canine cardiac myocytes. Molecular basis of ionotropic and toxic effects of digitalis. J Biol Chem 262:6842-6848.

Mazzone SB, Canning BJ (2002) Synergistic interactions between airway afferent nerve subtypes mediating reflex bronchospasm in guinea pigs. Am J Physiol Reg Int Comp Physiol 283:R86-R98.

Mazzone SB, Canning BJ (2003) Identification of the afferent nerves mediating cough in guinea pigs. FASEB J 17:A822.
Mazzone SB, McGovern AE (2006) Na+-K+-2Cl-cotransporters and $\mathrm{Cl}$ channels regulate citric acid cough in guinea pigs. J Appl Physiol 101: 635-643.

Mazzone SB, McGovern AE (2008) Immunohistochemical characterization of nodose cough receptor neurons projecting to the trachea of guinea pigs. Cough 4:9.

Mazzone SB, Mori N, Burman M, Palovich M, Belmonte KE, Canning BJ (2006) Fluorescent styryl dyes FM1-43 and FM2-10 are muscarinic receptor antagonists: intravital visualization of receptor occupancy. J Physiol 575:23-35.

McKeon A, Ozelius LJ, Hardiman O, Greenway MJ, Pittock SJ (2007) Heterogeneity of presentation and outcome in the Irish rapid-onset dystoniaparkinsonism kindred. Mov Disord 22:1325-1327.

Meyers JR, MacDonald RB, Duggan A, Lenzi D, Standaert DG, Corwin JT, Corey DP (2003) Lighting up the senses: FM1-43 loading of sensory cells through nonselective ion channels. J Neurosci 23:4054-4065.

Morice AH, McGarvey L, Pavord I (2006) Recommendations for the management of cough in adults. Thorax 61 [Suppl 1]:i1-i24.

Moseley AE, Williams MT, Schaefer TL, Bohanan CS, Neumann JC, Behbehani MM, Vorhees CV, Lingrel JB (2007) Deficiency in Na,K-ATPase alpha isoform genes alters spatial learning, motor activity, and anxiety in mice. J Neurosci 27:616-626.

Munzer JS, Daly SE, Jewell-Motz EA, Lingrel JB, Blostein R (1994) Tissue and isoform-specific kinetic behavior of the Na, K-ATPase. J Biol Chem 269:16668-16676.

Nishikawa S, Sasaki F (1996) Internalization of styryl dye FM1-43 in the hair cells of lateral line organs in Xenopus larvae. J Histochem Cytochem 44:733-741.

Pedersen M, Roudna M, Beutner S, Birmes M, Reifers B, Martin HD, Apell HJ (2002) Detection of charge movements in ion pumps by a family of styryl dyes. J Membr Biol 185:221-236.

Ribchester RR, Mao F, Betz WJ (1994) Optical measurements of activitydependent membrane recycling in motor nerve terminals of mammalian skeletal muscle. Proc Biol Sci 255:61-66.

Ricco MM, Kummer W, Biglari B, Myers AC, Undem BJ (1996) Interganglionic segregation of distinct vagal afferent fibre phenotypes in guineapig airways. J Physiol 496:521-530.

Ryan TA, Reuter H, Wendland B, Schweizer FE, Tsien RW, Smith SJ (1993) The kinetics of synaptic vesicle recycling measured at single presynaptic boutons. Neuron 11:713-724.

Smith Hammond CA, Goldstein LB (2006) Cough and aspiration of food and liquids due to oral-pharyngeal dysphagia: ACCP evidence-based clinical practice guidelines. Chest 129 [ 1 Suppl]:154S-168S.

Süudhof TC (2008) Neurotransmitter release. Handb Exp Pharmacol 184:1-21.

Undem BJ, Chuaychoo B, Lee MG, Weinreich D, Myers AC, Kollarik M (2004) Subtypes of vagal afferent C-fibres in guinea-pig lungs. J Physiol 556:905-917.

Watanabe N, Horie S, Michael GJ, Keir S, Spina D, Page CP, Priestley JV (2006) Immunohistochemical co-localization of transient receptor potential vanilloid (TRPV) 1 and sensory neuropeptides in the guinea-pig respiratory system. Neuroscience 141:1533-1543.

Yu J, Wang YF, Zhang JW (2003) Structure of slowly adapting pulmonary stretch receptors in the lung periphery. J Appl Physiol 95:385-393. 